\title{
The Developmental Challenge to the Paradox of Pain
}

\author{
Kevin Reuter \\ Please only quote the published version: \\ http://link.springer.com/article/10.1007\%2Fs10670-016-9816-8 \\ Published in Erkenntnis 2016
}

\begin{abstract}
People seem to perceive and locate pains in bodily locations, but also seem to conceive of pains as mental states that can be introspected. However, pains cannot be both bodily and mental, at least according to most conceptions of these two categories: mental states are not the kind of entities that inhabit body parts. How are we to resolve this paradox of pain (Aydede, 2006a; Hill, 2006)? In this paper, I put forward what I call the 'Developmental Challenge', tackling the second pillar of this paradox, i.e. the introspectionist (or mental-state) view of pain according to which (A) genuine pain reports are introspective reports. This view forms an inconsistent triad with two other widely held positions: (B) young children make genuine pain reports, and (C) young children do not make introspective reports. After introducing the paradox and the introspectionist view of pain in part 1, I present the developmental challenge (section 2), and defend both (B) and (C) in section 3. In section 4, I conclude that the inconsistent triad can only be resolved by reconsidering the introspectionist view of pain. In discussing three potential factors that lead to the puzzling intricacies of our concept of pain, I argue that the concept of pain might not be paradoxical after all.
\end{abstract}




\section{The Paradox of Pain and the Introspectionist View}

During the last decade, philosophers working on the topic of pain have highlighted a serious tension between the bodily and mental aspects of pain, which has come to be known as the paradox of pain (Aydede, 2006a; Hill, 2006). On the one hand, pain reports reveal that people locate pains in body parts, such as fingers or ankles. On the other hand, people seem to conceive of pains as mental states: An analysis of our common-sense conception of pain reveals that people largely think of pains as mental entities (Aydede, 2006a). Hasty attempts to overturn one of the two pillars of this paradox fail. People's pain reports are not just linguistic expressions with a semantics that is independent of the phenomenal character of experiences of pain: People locate pains in toes and elbows because this is where they feel pains to be. Rejecting the view that pains are mental states appears equally implausible. Pains seem to have all the characteristics typical of mental states: pains are considered to be private, subjective states that require an owner and cannot be hallucinated.

Both pillars of the paradox seem to be unshakable to the extent that some philosophers are prepared to bite the bullet and accept the conclusion of the paradox, thereby challenging the standard division of mind and body, e.g. Hyman (2003) argues that pains are both sensations of sentient beings and located where we feel them to be. However, people do not locate thoughts and desires, visual and auditory experiences, emotions and imaginations, in extra-mental space. Thus, the paradox seems to arise solely for bodily sensations of which pain is the most prominent example. It is arguably 
the restricted domain of the paradox that motivates philosophers to reject the antiCartesian conclusion of the paradox and to seek a less revolutionary solution to it.

One of those solutions has been put forward by Christopher Hill, who proposes an eliminativist conclusion: "We can remove the paradox of pain by replacing the concept [of pain] with two new ones" (2009, p. 189). Whereas one of these concepts would track disturbances in the body, reflecting the reported location of pains in the body, the other would refer to feelings of pain and satisfy the mental aspect of our concept of pain. Other philosophers have been less convinced that the mental aspect of pain is a dominant strand in our common-sense understanding of pain, and argue in favor of a purely perceptual view, which takes pains to be bodily states that we perceive when we feel pains. Whereas Sytsma (2010) shows that people do not tend to consider pains to be private in the case of conjoined twins, Reuter (2011) uses web-statistical data on the occurrences of the phrases 'feeling pain' and 'having pain' to argue for a distinction between the appearance and reality of pain, thereby putting into doubt the proclaimed subjectivity of pains.

It is far more common among both scientists and philosophers, however, to embrace the view that pains are mental states and that people think of pains as mental states. The International Association for the Study of Pain defines pain as an unpleasant emotional and sensory experience that is associated with actual or potential tissue damage, and most scientists describe pains in accordance with the IASP definition. Similarly, philosophers who work on theories of introspection and self-knowledge take people's awareness of pain to be a classic example of introspective awareness, i.e. awareness of a 
mental state. The term awareness, however, is ambiguous and can be understood in a conceptual and non-conceptual way. It has been acknowledged that the mere feeling of pain is not sufficient for introspective knowledge of pain, e.g. Seager argues that

"feeling a pain does not by itself constitute any kind of introspective knowledge. [...] To suppose otherwise would entail crediting all creatures who can feel pain with introspective knowledge about their own minds and while cats, for example, can surely feel pain they do not, I think, engage in introspection." (2000, p. 53)

Seager then identifies what he takes to be the missing ingredient for the attribution of introspective knowledge of one's pain: "Introspective knowledge of, for example, our own pains requires consciousness of the pain, plus the knowledge that this is a pain, or that I am in a state that hurts or something along these lines." (2000, p. 62, my italics). According to Seager, whenever people feel a pain and report that they have a pain based on their feeling the pain, they have introspective knowledge of their pain. The main reason for why philosophers hold that these pain reports are indeed introspective reports is that people seem to consider pains to be (i) private, (ii) subjective states that require an owner, and (iii) cannot be hallucinated. These three characteristics are often summarized (see e.g. Dretske, 2006; Kripke, 1980; McGinn, 1982) by the claim that it is impossible to distinguish the appearance from the reality of pain. According to this claim, the conceptual role of pain seems to be determined by the following two conditionals:

(Subjectivity of Pain) If a person has a pain, then the person feels a pain. 
(No Hallucination) If a person feels a pain, then the person has a pain.

Regarding the subjectivity of pains, it is argued that it would be absurd for people to believe that pains are lingering in their body without them being aware of them, e.g. Aydede states: "That pain is a subjective experience seems to be a truism." (2009) And Lewis writes: "Pain is a feeling. Surely that is uncontroversial." (1980, p.222) Equally implausible seems to be the suggestion that people can feel a pain without there really being any pain, e.g. Block asserts that "we do not acknowledge pain hallucinations, [i.e.] cases where it seems that I have a pain but in fact there is no pain" (2006, p. 138). Not all philosophers, however, agree that the common-sense conception of pain rules out unfelt pains and pain hallucinations. ${ }^{\mathrm{i}}$ The putative lack of an appearance-reality distinction for pains contrasts with our understanding of ordinary objects of perception. Not only do people believe that objects of perception continue to exist without being perceived, they also hold that it is possible to hallucinate perceptual objects, e.g. people may genuinely report scents of burned toast and the beating of drums when they are not really perceived. From these considerations regarding the awareness of pain we can state what I hereafter call the introspectionist view of pain:

(A) Genuine pain reports are introspective reports.

This statement should be read as a universally quantified statement, i.e. that all genuine pain reports are introspective reports. In using the term genuine pain reports I mean pain reports that are (i) made when a person really does have a pain, and (ii) are based on the feeling of the pain. Unfortunately, very few scholars discuss how the introspectionist 
view of pain can be squared with the first pillar of the paradox of pain, i.e. that people locate pains in body parts. Representationalists like Tye (2006) have developed an interesting solution to the paradox which comes, however, at a significant cost. Accordingly, experiences of pain represent bodily disorders in bodily locations. In order to explain why people locate pains in body parts, Tye states:

"The term pain in one usage, applies to the experience; in another, it applies to the quality represented, insofar as (and only insofar as) it is within the content of a pain experience." (Tye, 2006, p. 101, my italics).

Aydede discusses a similar suggestion on behalf of the representationalist:

"Upon reflection, however, we may realize that in uttering I feel a sharp pain in the back of my right hand, I actually attribute an intentional feeling state to myself which in turn attributes a physical disturbance to my hand. The colloquial ways of speaking just jumble the pain with the disturbance, and thus confuse and mislead us." (Aydede, 2009).

Thus, representationalists reject the view that pains are literally located in body parts. In order to explain why people apparently report pains to be in body parts, Tye maintains that when people are aware of a pain experience, they may label the content of such an experience as pain despite the fact that pains are experiences that actually represent bodily disorders. Aydede suggests that one might consider the semantics of pain expressions to be confused and that upon reflection we can realize that we merely 
attribute disorders to bodily locations. The concept of pain, therefore, stands in stark contrast to our concept of color. Whereas the term 'color' refers to properties of extramental objects, our concept of pain refers to the experience of pain, and not to disorders in body parts.

While various objections ${ }^{\mathrm{ii}}$ have been raised against these suggestions - most notably by Aydede - there is a more general problem for anyone holding the view that pain reports are introspective. Both Aydede and Tye maintain that pain reports are introspective reports even if the term 'pain' sometimes refers to the quality of the bodily disturbance in a non-mental location. They primarily do so because they believe that the commonsense conception regards pains to be private, subjective states that cannot be hallucinated. Hence, the criteria for why pain reports are classified as introspective continue to hold: A "pain report is an introspective report from the very beginning, hence not a perceptual report" (Aydede, 2006b, p. 134). Against the position that pain reports are always introspective (from the very beginning), I will now present what I call the 'Developmental Challenge', which will be presented in form of an inconsistent triad. The purpose of this challenge will not be merely negative, however. I believe that raising this challenge directs much needed attention to the question of how the paradox is supposed to arise in the first place. In the last section I will therefore highlight the factors that I believe lead to the puzzling intricacies of our concept of pain. 


\section{The Inconsistent Triad of Pain}

The introspectionist position (A) is confronted by an inconsistent triad made up of the following three propositions:
(A) Genuine pain reports are introspective reports.
(B) Young children ${ }^{\mathrm{iii}}$ make genuine pain reports.
(C) Young children do not make introspective reports.

These three claims are conjointly inconsistent: (A) \& (B) yield 'Young children make introspective reports', which directly contradicts (C). Thus, at least one of the three propositions must be false to avoid endorsing an inconsistent position. Before I discuss possible ways for rejecting claims (B) and (C) in greater detail in the next section, let me first show why (B) and (C) are widely held claims.

Infant studies show that neonates have a complex response pattern to pain - including facial and other behavioral expressions - before learned response mechanisms are acquired (Grunau \& Craig, 1983). Around the age of 12-17 months, small children express their pains by repetitive sounds like 'ow - ow'. During the subsequent stage between 18-24 months - various pain-referring words (e.g. 'pain', 'sore', 'ache') enter into children's vocabulary and children start to describe the location of their pains (Franck et al., 2010; Stanford et al., 2005). In an extensive study involving 1716 parents, Franck et al. (2010) determined that by the age of around 3 years, children's expressive ability includes complex structures, e.g. 'I have an ow' and descriptive 
words, e.g. 'stubbed' indicating a causal understanding of the origins of pain. Thus, not only are most 3-year old children capable of feeling pain, they are also capable of correctly reporting that parts of their body are painful. Given this data, it seems therefore plausible to conclude that (B) of the inconsistent triad is true. In the next section I will analyze various suggestions on how to rebut proposition (B) in spite of the empirical evidence.

It is also widely accepted that a three-year-old child is not able to make introspective reports yet (Flavell et al., 1990; Fabricius et al., 2010). There are several standardized tasks, e.g. false-belief tasks, appearance-reality tasks, that are often used in order to probe children's conceptual abilities. To fail these tasks is usually interpreted as a sign of lacking an explicit theory of mind, i.e. the ability to refer to and reason about mental states. These tasks demonstrate that most children explicitly attribute beliefs and start to distinguish appearance from reality when they are between three-and-a-half and five years old. ${ }^{\text {iv }}$ From five years onwards, a majority of children manage to correctly distinguish true from apparent identities if questions about the appearance and reality of objects and properties are asked in a child-friendly manner. In some non-industrialized non-Western cultures, the age at which children pass these tasks may be much higher, e.g. most 8-years-old Junín Quechua children in Peru were not able to respond to questions in a standard false-belief task setting correctly (Vinden, 1996). During the last decade, so-called implicit false belief tasks have been conducted and interpreted to show that children may possess a theory of mind earlier than so far maintained, e.g. Onishi et al. (2005), Samson et al. (2010). How to correctly interpret these experiments is a matter of controversy. As I am concerned with introspective reports only, which 
require an explicit reference to mental states, these debates affect the current discussion only peripherally. It seems therefore that developmental studies regarding children's ability to pass explicit false-belief and appearance-reality tasks, show that young children do not yet make introspective statements. Consequently, $(\mathrm{C})$ of the inconsistent triad also seems to be true.

Let us summarize our findings so far before we delve into a more thorough discussion: First, I have argued that pain reports are considered to be introspective because people think and talk about pains as private, subjective states that cannot be hallucinated. Second, empirical studies show that young children make pain reports. Thirdly, a large majority of the participants in this debate, including both philosophers and psychologists, agree that in order to be capable of making introspective statements about one's sensory experiences, it is necessary to be able to distinguish the appearance from the reality of an object or an object's property (Dretske, 1995; Gopnik et al., 1988; Taylor \& Flavell, 1984; Tye, 1995). However, if children have not yet developed an understanding of these notions, then how can children's pain reports be classified as introspective? We can therefore challenge the second pillar of the paradox of pain, i.e. the introspectionist position, by joining these three claims which form the inconsistent triad that I have already stated above:
(A) Genuine pain reports are introspective reports.
(B) Young children make genuine pain reports.
(C) Young children do not make introspective reports. 
It is obvious that it is impossible to consistently entertain all three propositions (A), (B) or $(\mathrm{C})$. How can we respond to this challenge?

\section{Responding to the Developmental Challenge}

The introduction of the inconsistent triad and the motivation of its propositions in the last section suggest that the paradoxical nature of pain may not arise for younger children. Hence, it seems that those who would like to uphold the introspectionist view about people's awareness of pain need to respond to the developmental challenge by either revising or restricting the introspectionist view of pain, or by rejecting one of the additional propositions of the inconsistent triad. This section analyzes in greater detail whether it is plausible to reject or at least doubt either (B) or (C).

1. Rejecting (B): It is not the case (or has not yet been conclusively shown) that young children make genuine pain reports.

2. Rejecting (C): It is not the case (or has not yet been conclusively shown) that young children do not make introspective reports.

\subsection{Do Young Children Report Pains?}

The simplest way to reject the claim that young children make genuine pain reports is to deny that children actually experience what we call 'pains'. However, this is merely a theoretical possibility. This response amounts to stating that children do not feel pains 
but something else, e.g. schpains. However, there is neither neurophysiological nor behavioral evidence for this proposal. Instead, "the afferent nociceptive system is completely developed by twenty-nine weeks gestation" (Hardcastle, 2001, p. 197). Although it is true that children's expressive pain-behavior can be quite different from the behavior of adults - mostly because many adults do not want to be perceived as suffering - the basic neurophysiological and behavioral responses are very much the same (Mathew \& Mathew, 2003; Rushfort \& Levene, 1994). Young children and adults show the same responses in terms of withdrawal, avoidance, protection, and instinctive expressive behavior. Thus, the empirical results on pain perception in infants make it very unlikely that children's pain experiences are different from those of adults.

A more promising move for rejecting claim (B) is to argue that small children do not yet have the concept of pain. Accordingly, children do not yet report pains despite them seemingly being able to successfully communicate to other people that something is wrong with their body based on their bodily sensations. Whether this objection can succeed largely depends on the possession conditions for the concept pain. Unfortunately, stating the possession conditions for concepts is notoriously difficult. However, we can cut this discussion somewhat short by highlighting that for the purpose of our debate, we are interested in situations in which a pain report is made because a pain was recognized. In these situations, we can therefore assume that the concept pain is a recognitional concept. This assumption seems to be shared by most protagonists of the debate (Tye, 2006; Aydede, 2006a; Hill, 2006). Jerry Fodor argues that a concept is recognitional if "among its possession conditions is the ability to recognize at least some things that fall under the concept as things that fall under the 
concept" (1998, p. 1). A purely recognitional concept of pain is a recognitional concept that has no other possession conditions but dispositions for recognizing instances of pain. If the concept pain is a purely recognitional concept, then children possess the concept pain if they correctly recognize pains in body parts, an ability that we have seen can be attributed to almost all 3-year olds. Thus, under a purely recognitional reading of the concept pain, (B) holds. It is of course possible that people recognize pains through an introspective process. This possibility will be considered in the next section. For now, we are only concerned with whether it is at all plausible to deny that young children make genuine pain reports.

It might be argued that the concept pain is not a purely recognitional concept. Instead, the concept of pain may have among its possession conditions non-recognitional features. Such a condition could be, e.g. that a person possesses the concept pain only if that person believes that pains cannot exist without being felt. Hill (2006) adopts such a position. He states among other conditions that in order to possess the concept of pain one must be disposed to reject the proposition that there is a pain (in one's ankle), unless one feels a pain (in one's ankle). ${ }^{\mathrm{v}}$ There are three reasons why I believe such additional possession conditions should be rejected. First, if Hill is correct, then a child who claims that there is a pain in her ankle, but that she can only feel it sometimes, would not possess the concept of pain. This conclusion seems to be counterintuitive, especially if the child has learned to identify and locate pains correctly when they occur, and hence is successful in communicating with adults whether or not she has a pain. Second, experiments have shown (e.g. Sytsma, 2010; Reuter, 2011; Reuter et al., 2014) that many adults do not consider pains to be subjective and that pains can actually be 
hallucinated. It is one thing to respond to these results by pointing out that some people may make wrong inferences regarding their own or other people's pains. However, if Hill is correct, then we would need to deny that these people actually possess the concept of pain, which seems too strong a claim. It seems to be more plausible to acknowledge that these people do possess the concept of pain, but draw different inferences about their pains than other people.

Third, rejecting a non-introspective account by holding that the subjectivity and privacy condition are necessary possession conditions of the concept pain, and that young children do not therefore possess the concept of pain, begs the question against a nonintrospective account if no independent motivation for these possession conditions is presented. However, it is very unlikely that the incorporation of the privacy and subjectivity condition into the possession conditions of the concept pain can be argued for on independent grounds. Philosophers do not present any independent evidence for the claim that pains are mental states other than referring to our common-sense understanding of pain:

"That pains are necessarily private and necessarily owned is part of our folk conception of pain and it requires explanation. The obvious explanation is that pain is a feeling or an experience of a certain sort. [... This] is part of our commonsense conception." (Tye, 2006, p. 100, my italics) 
"[According to the] common-sense conception of pain [...] pains are sensations with essential privacy, subjectivity, self-intimation, and incorrigibility." (Aydede, 2009, my italics)

The view that pains are considered to be mental states stands and falls with our common-sense conception of pain, and does not seem to be motivated independently. Hence, denying children the possession of the concept pain, not only seems to be a counterintuitive move, given that children successfully communicate the existence of pains, it also begs the question against the possibility of a non-introspective view of pain.

\subsection{Do Young Children Conceive of Pains as Mental States?}

Another way to dismiss the developmental challenge I have raised against the existence of the paradox of pain in general, and the introspectionist view in particular, would be to deny (C), i.e. deny that young children do not make introspective reports. In section 2 , I provided initial reasons for endorsing (C): Studies by Flavell et al. (1990) and Fabricius et al. (2010) show that young children do not pass appearance-reality tasks, and hence cannot yet be granted with the possession of an explicit theory of mind. Extrapolating from their data, it seems reasonable to suppose that this inability to make introspective reports also holds for pains. However, the psychological evidence does not show that young children don't make introspective reports about pains but that they don't do so only about their sensory states. Thus, it might be argued that, in contrast to sensory states, young children apply mental concepts to pain, and thus conceive of pains as 
mental states. According to this view, whereas 3-4-year old children do not pass appearance-reality tasks for sensory experiences, they find it easy to do so when it comes to pains. This position would be itself a fascinating consequence of our discussion: So far, no one seems to have argued that pains are the first mental states that children are conceptually aware of.

But what would it mean to pass an appearance-reality task when it comes to pains? In appearance-reality tasks, children are usually tested on their ability to distinguish the appearance of objects from the real nature of those objects. According to representationalist accounts of perception, this amounts to distinguishing what is represented from what really is the case, e.g. the represented reddish color of a toy car behind a red filter from its real color white. While the introspectionist claims that the appearance-reality distinction does not apply to pains themselves, we have seen that they attempt to dissolve the paradox of pain by distinguishing pains from what pains represent, i.e. tissue damage or bodily disorder (Aydede, 2009; Tye, 2006). ${ }^{\mathrm{vi}}$ Consequently, we can posit a (at least necessary) criterion for attributing the ability to conceive of pains as mental states by investigating children's skills to distinguish pains from the bodily disorders pains may represent: If children manage to successfully distinguish pain experiences from the bodily damage, then one might argue that those children pass an appearance-reality task for bodily sensations. Whereas this would not be clear evidence that children conceive of pains as mental states, it would at least indicate a more sophisticated understanding of pains as being independent of bodily disturbances. If, on the other hand, children think of pains as things or properties of 
objects in bodily parts, then it can hardly be concluded that children possess a theory of mind in regards to pains.

A survey of the literature reveals that there is no evidence that younger children conceive of pains as distinct from the bodily disorders experiences of pains are supposed to be independent from. In a large-scale study involving 680 school children in Ireland, Gaffney et al. (1986) investigated how children between the age of 5 and 14 think about pains, and conclude that 5-7 year-olds have "a view of pain which is concrete, limited to certain locations in the body, perceptually dominated [and] passive" (1986, p. 114). These results have been confirmed by Esteve \& Marquina-Aponte (2011) who surveyed the responses of 4-6 year olds towards various questions about the nature of pain, and claim that these children largely conceive of pain as a thing or a physical injury. Given this psychological data and its coherence with standard experiments to test children's understanding of mental states, it seems that children can self-attribute pains as mental states no sooner than sensory experiences or propositional attitudes. In contrast to the introspectionist's claim, the study by Esteve \& MarquinaAponte (2011) suggests that children start to think of pains as partially independent of physical injuries not before they are 8 years old.

So far I have closely connected the conditions that need to be fulfilled for making introspective reports about sensory experiences with those for classifying pain reports as introspective. This approach highlights the importance of the appearance-reality distinction (and its related notions of privacy, subjectivity and hallucination) and is inspired by the main protagonists of the debate. However, one may question this 
approach and instead point towards statements of emotions like 'I am sad' or 'I am happy'. If these reports are introspective and also made by young children, then claim (C) of the inconsistent triad is false. ${ }^{\text {vii }}$ It would take us too far afield to discuss young children's ability to express emotions in greater detail. It seems, however, that a plausible case can be made against classifying young children's statements of emotions as introspective reports. Alridge \& Wood argue that academic research findings often inflate children's ability to report emotions. In a study involving 56 children, they show that "no 5-year old, nor the majority of 6- or 7-year-olds, could [verbally] express fear, anger and anxiety" (1997, p. 1231). Instead, 5-year-olds use the single word 'happy' to describe positive situations, and the single word 'sad' to describe negative situations. Thus, the debate on whether claims of 3-year olds such as 'I am happy' and 'I am sad' should be classified as introspective reports or merely as responses elicited by positive or negative situations, is far from being settled. ${ }^{\text {viii }}$

A similar objection can be made when considering statements of the form 'I see an $\mathrm{x}$ ', or 'I hear y': statements that children utter before they pass appearance-reality tasks. ${ }^{\text {ix }}$ These statements are sometimes classified as introspective statements (Carruthers, 2007; Nichols \& Stich, 2003). Whereas there might indeed be a notion of seeing and hearing, the use of which indicates introspective awareness, the more common notion of perception diverges from the one proposed by Carruthers and Stich \& Nichols. Child argues that "the concept of perception is the concept of a way of finding out about an objective world, independent of us" (1994, p.142, my italics), and even Carruthers claims that "there is, indeed, a simpler concept of seeing, grounded in the capacity to track eye-direction and line of sight. [...] To say, in this sense, that someone sees green is just to say that there is some green in the line in which their eyes are pointed - no 
mental state needs to be attributed" (2007). Given the difficulties of children to pass appearance-reality tasks, it is thus more plausible to assume that children use this simpler concept of seeing before they have developed a theory of mind.

There is, however, an altogether different strategy for rejecting statement (C). A long tradition in the philosophy of mind conceives of introspection in terms of an inner sense model, e.g. Armstrong (1968), Lycan (1997). According to inner sense theorists, people usually report mental states after having used a non-conceptual sensory-like process. Advocates of process-based accounts of introspection claim that introspection resembles perception in certain respects, most importantly in that the introspecting person can direct her focus to several aspects of her first-order experience by introspectively attending to her sensory experiences. Applying this alternative account of introspection to our discussion at hand, inner-sense theorists can argue that all pain reports, also those made by young children, are introspective reports because even young children use an introspective mechanism to report their pains. Due to the lack of conceptual sophistication, these children might not yet conceive of pains as subjective mental states. Nonetheless, those philosophers will argue that we should classify all reports that are based on such an introspective mechanism as introspective reports. Note, however, that this alternative account would not constitute a possible response for most of the main protagonists of the debate on the paradox of pain (e.g. Hill, Tye), because they conceive the non-conceptual part of pain awareness to be a perceptual but not an introspective process. 
In order to evaluate this proposal, we need to get clearer on the relation between the mechanism underlying the perception of bodily disorders in body parts and any putative introspective mechanism. It seems that there are two ways in which the introspective mechanism can be said to operate. First, one may argue that parts of the pain mechanism that are usually identified as perceptual are actually introspective: If correct, we should label a certain part of the mechanism 'introspective'. Second, the introspective mechanism may operate on top of (and causally after) the perceptual mechanism. I think that both positions have little to speak in favor of them. The first version of the proposal leads at best to a verbal dispute, i.e. whether we prefer to call attention to pains introspective or perceptual. However, given that attention to pains is directed outwards towards body parts, and more specifically to the location of pains, there seems to be no reason to re-label a part of the perceptual system 'introspective'.

A more promising view is the second version of the proposal. According to this view, there is an introspective attention mechanism on top of the pain pathways that makes us aware of pain experiences. While this account of introspection has still several contemporary defenders (e.g. Gertler, 2009; Lycan, 2007, Schwitzgebel, 2011), its popularity has somewhat decreased in course of the increased acceptance of the transparency thesis (Harman, 1990). This thesis states that in introspection people's attention slips right through their experiences. Accordingly, when a person tries to introspect her pain experience, her attention will automatically focus on qualities of the bodily disorder or bodily damage. Whether or not the transparency thesis is true for pain experiences (see Aydede (manuscript) for a sceptical position), the phenomenal datum that the transparency thesis rests on, is almost universally accepted: the qualities that a person is aware of when she introspects an experience of pain, will appear as qualitative 
properties of the bodily state. Thus, the claim that experiences are transparent is often taken to be a decisive objection against process-based accounts of introspection, as it seems to demonstrate that there is no indication that such an introspective process occurs. It might be objected, however, that the introspective mechanism, while not manifesting itself in people's reports and phenomenal experiences, is required to explain why more mature children and adults conceive of pains as private, subjective mental states. This objection may sound odd, given that its advocates need to argue that young children do not yet conceive of pains as mental states despite using an introspective mechanism because they lack conceptual maturity. Thus, conceptual sophistication seems to be doing the explanatory work and not the introspective mechanism. However, the objection continues, the introspective mechanism enables conceptual maturity and is our best explanation for why older children think of pains as mental states. Just as the traditional sense modalities shape and refine our perceptual concepts, the introspective sense modality shapes and refines our mental state concepts. At this stage, the best way to deal with this objection against the developmental challenge, is to provide alternative explanations that not only dispense with the postulation of an introspective mechanism but can actually make predictions about people's development of concepts that can be empirically tested. This will be the task of the next and last section of this paper.

\section{How does the Paradox of Pain Arise?}


In the previous two sections, I have raised (section 2) and defended (section 3) what I call the developmental challenge. One of the two pillars of the paradox states that (A) Genuine pain reports are introspective reports. However, combined with (B) Young children make genuine pain reports, and (C) Young children do not make introspective reports, we are faced with an inconsistent triad. My analysis of this triad in the previous sections led me to argue that it is implausible to reject either (B) or (C). Thus, to avoid the inconsistency, we need to drop (A), i.e. the introspectionist view that all genuine pain reports are introspective reports. This means that (i) the paradox of pain does not arise for young children, and that (ii) at a minimum we need to refine and qualify the introspectionist view of pain.

If my challenge stands, then young children's awareness of pain should be characterized as fully perceptual, i.e. young children conceive of pains as bodily states. We can now respond in three possible ways to this developmental challenge: First, we can hold that an adult's awareness of pain is also purely perceptual (and the paradox as such dissolves). Second, one might believe that our awareness of pain is ambiguous: whereas some pain reports are recognitional perceptual reports, others are truly introspective statements. Third, we can maintain that a mature awareness of pain is always introspective. Anyone who argues for either the second or third option, i.e. the view that (some or all) pain reports become introspective with advanced conceptual sophistication, the following important question arises: which factors influence the transformation of a former perceptual report into an introspective report? An obvious answer would be to highlight that children realize at some stage in their development that pains are private, subjective states that require an owner. Hardcastle, for example, 
claims that "certainly as children grow and mature, their sense of what feeling pain is will change and become more precise as their mnemonic, cognitive, and emotive capacities grow and mature as well” (2001, p. 194).

Surprisingly though, there are hardly any investigations into how this transformation is supposed to take place. ${ }^{\mathrm{x}}$ Compare this to the massive research community that attempts to determine when and how children develop a theory of mind for propositional attitudes and visual experiences. In this last section, I discuss three factors that, so I argue, have an important impact on how people's concept of pain develops. I believe that further progress in our understanding of people's concept of pain can be expected from studying these three factors.

Arguably the most important factor that shapes the development of the concept of pain in a child is the constraint that every human body is connected only to a single mind/brain, hereafter called one body - one mind constraint. This constraint is only violated in conjoined twins who are extremely rare and often die within the first few months of their lives. Whereas visual properties of body surfaces are in principle publicly accessible, properties of interior states of the body, including certain properties of the skin, are naturally accessible through nerve signals that are connected to a single mind only. Modern technologies like x-ray and ultrasonography now provide ways to access interior states of the body. However, in normal circumstances - circumstances that determine the way we use ordinary concepts - people have no direct access to other people's interior states of the body. Importantly, it seems that several properties that are 
often claimed to be evidence that the concept pain is a mental concept, develop because of the one body - one mind constraint:

Privacy: There can be little doubt that for most people pains are private. However, the private nature of pains might only be a contingent matter - dependent on the fact that each person has exclusive direct access to her own body. The case of conjoined twins provides a test bed for the status of the privacy of pains. Thus, one might argue that a pain that seems to occur in a shared body part is felt by both twins, and is thus a public object for the community of the twins.

Incorrigibility: Given that in most cases people have no direct access to the pains of other people, they have no basis for, and hence never correct other people's pain reports. Whatever the person reports about her pain gains the status of being incorrigible. Medical practitioners might of course interrogate patients about their pains in a way that seems to suggest that they have better knowledge of a person's pain than the pain-patient herself. However, the ultimate authority about her pain remains (or at least should remain) with the pain-patient (Sullivan, 2003).

Certainty: A direct consequence of the lack of any disagreement with a person's pain report is that people consider their access to their own pains to be highly reliable. Thus, pain reports are considered to be certain.

Subjectivity: Given that people consider the access to their pains highly reliable, there is no reason for them to posit the existence of pains, if they cannot feel any pains. Pains are considered subjective states that require an owner. 
The one body - one mind constraint is thus likely to be largely responsible for the plausibility of the introspectionist view of pain. Note, however, that people's concept of pain would be shaped in the way I have sketched above, even if pains are bodily and not mental entities: People do have private access not only to their mental states but also to bodily states, and the incorrigibility and certainty of pain reports may mislead many people to think of pains as subjective states. Thus, investigating the features that clearly signify pains to be mental states, is a difficult endeavor. One way to disengage necessary mental from contingent bodily privacy, however, would be to determine whether conjoined twins have a concept of pain that diverges from other people's concept in its introspective characteristics. Due to the rare occurrence of conjoined twins, however, other empirical investigatory means may be necessary, e.g. manipulating people's visual body image in virtual realities in which people share certain body parts with other people, or directly asking people to imagine sharing body parts with others (Sytsma, 2010). In (3.2.), I have argued that we should only posit an introspective attention mechanism if no other explanations are in sight. The existence and likely importance of the 'one body - one mind' constraint seems to be a much more plausible candidate to explain the conceptual role of pain.

If the one body - one mind constraint is largely responsible for the way we think about pains, then concepts of other bodily sensations should be similarly governed by that constraint. ${ }^{\mathrm{xi}}$ We have to distinguish, however, intransitive sensations like itches and tickles from transitive sensations like sensations of warmth, pressure, and proprioceptive states. All these sensations essentially involve the body, but only intransitive bodily sensations like itches and tickles provide us with information about states that are accessible only to a single mind. In contrast, the warmth of external 
objects and the pressure they exert on body parts is publicly accessible. Similarly, while proprioceptive sensations are accessible only to a single mind, the objects that these sensations inform us about, namely the position and movement of one's body, can be verified or falsified from a third-person point of view. Hence, it is not surprising that the appearance-reality distinction can be successfully applied to objects and qualities, about which thermoception and proprioception inform us, e.g. 'It feels warm but it is not warm', 'it appears as if my hand is moving, but it is not moving'.

A second reason for why people believe pains to be mental states can be found in language-specific linguistic expressions and 'language games'. I briefly discuss two examples to illustrate this point. First, when people have strong or enduring pains in a certain body part, they often take painkillers to stop the body part from hurting. The English word 'painkiller' literally means that the pill kills the pain itself, and not merely the experience of pain, even if this might not be a proper description of what happens anatomically. In fact, analgesics, in contrast to anaesthetics, do not prevent nerve signals from bodily disorders to reach the affective and somatosensoric parts of the brain, but act centrally in the brain. Our understanding of painkillers furthermore seems to support the view that when the feeling of pain ceases due to the effect of painkillers, the pain itself is gone (Aydede, 2006b). This language game is not universal though. In the German language, painkillers are called 'schmerzstillende Mittel' which can be translated as pain-silencing appliances, suggesting that the pain does not vanish but rather continues to exist without 'being vocal' ${ }^{\text {xii }}$ Whether or not native Germans consider pains to stop when they take a 'pain-silencing pill' is certainly an interesting question that deserves further investigation. Second, the English phrase 'I am in pain' is 
idiosyncratic and does not have equivalent expressions in any other language that I have looked into. ${ }^{\text {xiii }}$ Interestingly, the phrase 'being in pain' does not attribute a pain to a body part but rather to a person (see e.g. Bain, 2007), and hereby resembles ascriptions of states of emotions, cp. 'I am sad'. This expression is also semantically impoverished in that it cannot be further specified where a pain is felt, e.g. it is semantically incoherent to claim 'I am in throbbing ankle-pain'. Arguably, the widespread and very frequent use of the phrase 'I am in pain' encourages people to think that emotions and bodily sensations have more in common than they might actually have, whereas in other languages, e.g. Spanish, French and Italian, a relational view between people and pains may be preferred. These example suggest that the inferential aspects of the concept of pain may depend on properties of the language in which the concept is embedded. In order to investigate this possibility, cross-cultural studies should be conducted that can reveal whether perceptual and introspective characteristics of our awareness of pain are shaped by cultural and linguistic circumstances.

A third source for older children's more sophisticated reasoning abilities about pains may be found in their advanced knowledge of other mental states by the age of six. At this age, children pass appearance-reality and false-belief tasks, indicating that they understand that mental states are representational - the arguably most important aspect of the mind. The study by Esteve et a. (2011) demonstrates that children conceive of pains as partially independent of physical injuries a few years after they pass false-belief tasks. Thus, it might well be the case that gaining knowledge about propositional attitudes and visual experiences fosters a more sophisticated understanding of pains perhaps as mental states. ${ }^{\text {xiv }}$ The dual component view of pain experiences, according to 
which pains have both sensory and affective elements, makes it not only more difficult for children to grasp the nature of pains, but makes it also more complicated to test children's conceptual abilities. Nonetheless, whereas established tasks exist to test children's abilities to reason about false beliefs and appearances in the traditional sense modalities, similar experiments for pains and other bodily sensations are currently lacking. Such experiments are urgently needed to detail the conceptual abilities of children in the domain of bodily sensations.

I have argued that if the developmental challenge succeeds, then young children's pain reports need to be classified as perceptual. In order to understand why the commonsense conception of pain suggests pain reports to be introspective, we need to investigate the various factors and contexts that shape the concept of pain in children and adults. In this section I have listed and discussed three factors that may influence the way we think and talk about pains. Importantly, none of these factors rules out the view that the common-sense conception about pains is mistaken. E.g., the privacy of pains may be merely contingent due to the one body - one mind constraint, which may also leads us to falsely believe that pains are subjective states. I do not maintain, however, that a determinate answer can be given without further empirical studies. The outcome of my discussion is consistent with the view that at least the majority of pain reports are not introspective but rather perceptual reports. Our concept of pain might not be paradoxical after all. 


\section{Conclusion}

In this paper I raised what I call the developmental challenge to the paradox of pain. This challenge attempts to dissolve the paradox by disputing the introspectionist view of pain (A). I have shown that the introspectionist view is constitutive of an inconsistent triad: (A) Genuine pain reports are introspective reports, (B) Young children make genuine pain reports, (C) Young children do not make introspective reports. By analyzing results from several developmental studies and by considering the possession conditions for the concept pain, I argued that we can neither reject that children make genuine pain reports (B), nor does it seem plausible to deny that young children do not make introspective reports (C). Consequently, I concluded that the introspectionist view (A) is not a generally valid claim, and that the paradox of pain does not hold for young children. My solution to the developmental challenge requires that we start to look for explanations of how the putative paradox of pain may arise during cognitive development. In order to make progress on how the concept of pain works, I have suggested to (i) determine the importance of the 'one body - one mind' constraint for the development of the concept pain, (ii) investigate how this development is shaped by the linguistic communities of speakers in which children grow up, and (iii) study how children develop the concept of pain in relation to the development of metacognitive abilities in other domains.

\section{Notes}


i As for the the subjectivity of pains, several counterexamples can be listed: (i) people sometimes say that pains wake them up, suggesting that they can exist unfelt; (ii) people also state that they feel the same pain again; (iii) it seems that we can be distracted from pains such that they exist without being felt, e.g. Lycan (2004, p. 106) has claimed that "given a mild pain that I have, I may be only very dimly and peripherally aware of it (assuming I am aware of it at all)." Referred pains and phantom-limb pains have been discussed (Pitcher, 1990) as instances in which people seem to be subject to pain illusions and pain hallucinations. Reuter et al. (2014) have presented empirical evidence showing that a majority of the participants in their studies accept the existence of pain hallucinations and pain illusions.

ii The suggestions offered by Aydede and Tye raise two well-known problems. First, people do not seem to be aware of either being confused (Aydede) or that the term pain has double duty (Tye). Thus, the proposal to solve the paradox immediately leads to a further riddle: how can people be either confused or ignorant about one of the most frequently applied concepts they possess. Second, Aydede raises the problem of focus. He states that "the typical result of a perceptual process is bringing the perceived object under a perceptual concept” (Aydede, 2009). Although people perceive bodily disorders by undergoing pain experiences, they do not, however, report the perceived object, i.e. the bodily disorder, but rather the pain experience itself. Thus, pain reports are highly idiosyncratic in that people use a perceptual process to make an introspective claim about a mental state.

iii In this essay I take young children to be between 2 and 4 years old.

${ }^{\text {iv }}$ The appearance-reality distinction plays a central part in this essay in two distinct but closely related ways. First, the impossibility to draw an appearance-reality distinction about $\mathrm{x}$ is taken to be a sufficient condition for categorizing $\mathrm{x}$ as a mental state. Hence, pains are often considered to be mental states because of the putative impossibility to draw an appearance-reality distinction for pains (Aydede, 2006a; Dretske, 2006; Hill, 2006). Second, the inability of a person to make an appearance-reality distinction is taken to be a sufficient condition for denying that this person is in possession of a theory of mind in regards to sensory states. Hence, failing appearance-reality tasks, is interpreted by many philosophers and psychologists (Baron-Cohen, 1989; Carruthers, 1996; Nichols \& Stich, 2003; Taylor \& Flavell, 1984) to mean that the person is not yet able to refer to sensory states of herself or others.

${ }^{v}$ Hill's exact wording is that "in order to possess the concept of pain one must be disposed to reject the proposition that one is in pain, unless one has a P-representation.” (2006, p. 82) 
vi Unfortunately, there is no consensus on what pains are supposed to represent. We can distinguish descriptivists like Tye (1995) who maintain that pains represent a certain type of disorder in one's body, and evaluationists like Bain (2013) and Tye (2006) who claim that pains represent disturbances which are in some sense bad for the person. In contrast to representationalists, imperativists (Klein, 2007; Martínez 2011) argue that pains do not have indicative but rather imperative contents.

vii It might still be the case that pain reports of young children are not introspective and hence (A) false, but whether pain reports are more similar to statements of emotion or more closely linked to statements about sensory experiences, would require further investigation.

${ }^{\text {viii }}$ An anonymous reviewer for this journal noted that statements like 'I am hungry' or 'I am thirsty' are also possible counterexamples to the claim that young children do not make introspective statements. The strength of these counterexamples depends on whether they are rightly classified as introspective or interoceptive. When used interoceptively, I take it that "I am hungry" merely refers to a state of my stomach and not to a state of my mind. I do agree though that the same utterance might be used introspectively (as has been argued by e.g. Shoemaker, 1996, p.211) and thus, refers to a mental state. It is at least doubtful, however, that children use hunger or thirst reports introspectively before they have learned the interoceptive use in order to demand food and liquid.

${ }^{\mathrm{ix}}$ This objection was raised by another anonymous reviewer for this journal.

${ }^{\mathrm{x}}$ The articles by Gaffney et al. (1986) and Esteve et al. (2011) describe different stages in the development of children's understanding of the concept pain, but these stages only allow for very limited conclusions about when 'mental' aspects enter into children's understanding of pain.

${ }^{x i}$ I thank two reviewers for this journal who have both raised this issue.

xii As a reviewer of this article has correctly pointed out, "schmerzstillende Mittel" is only one of two common translations of the English word "painkiller". The other is "Schmerzmittel". However, the term "Schmerzmittel" is silent about whether it is the pain or the pain experience that gets removed by the drug.

xiii An inquiry into 13 other, mostly European languages revealed that speakers of these languages have no equivalent expression to the English phrase 'being in pain'. People who speak these languages rather use expressions that are equivalent to 'having pain', 'feeling pain', 'it hurts', and 'it aches'. Thus, the 'being in pain'-phrase seems to be largely an idiosyncrasy of the English language. It therefore seems 
Challenge to Paradox of Pain

advisable to analyze the structure of the concept pain using expressions of pain that apply to other languages as well.

${ }^{\text {xiv }}$ The reverse claim, i.e. the possibility that children's understanding of other mental states is strongly influenced by children's awareness of pain, should not be excluded, however. 


\section{Compliance with Ethical Standards:}

The author declares that there is no conflict of interest. This research did not involve human participants or animals.

\section{References}

Alridge, M. \& Wood, J. (1997). Talking about feelings: Young children's ability to express emotions. Child Abuse \& Neglect, 21(2), 1221-1233.

Armstrong, D. (1968). A materialist theory of the mind. London: Routledge and Kegan Paul.

Aydede, M. (2006a). Introduction: A critical and quasi-historical essay on theories of pain. In M. Aydede (ed.), Pain: New Papers on its Nature and the Methodology of its Study. Cambridge, MA: MIT Press.

Aydede, M. (2006b). The main difficulty with pain. In M. Aydede (ed.), Pain: New Papers on its Nature and the Methodology of its Study. Cambridge, MA: MIT Press.

Aydede, M. (2009). Pain. The Stanford Encyclopedia of Philosophy, In E. Zalta (ed.), $\mathrm{URL}=<$ http://plato.stanford.edu/archives/spr2013/entries/pain/ $>$.

Bain, D. (2007). The location of pains. Philosophical Papers, 36(2), 171-205.

Bain, D. (2013). What makes pains unpleasant?. Philosophical Studies, 166(1), 69-89.

Baron-Cohen, S. (1989). Are autistic children "behaviorists"? An examination of their mental-physical and appearance-reality distinctions. Journal of Autism and Developmental disorders, 19(4), 579-600. 
Block, N. (2006). Bodily sensations as an obstacle for representationism. Pain: New Essays on Its Nature and the Methodology of Its Study, Cambridge, MA, The MIT Press. Bradford Books, 137-142.

Carruthers, P. (1996). Autism as mind-blindness: an elaboration and partial defence. in P. Carruthers, P. Smith (eds.) Theories of Theories of Mind, Cambridge: Cambridge University Press.

Carruthers, P. (2007). Higher-order theories of consciousness. The Stanford Encyclopedia of Philosophy, E. Zalta (ed.), URL = http://plato.stanford.edu/ archives/fall2009/entries/consciousness-higher/

Child, W. (1994). Causality, interpretation and the mind. Oxford: Clarendon Press.

Dretske, F. (1995). Naturalizing the mind. Cambridge, MA: MIT Press.

Dretske, F. (2006). The epistemology of pain. In M. Aydede (ed.), Pain: New Papers on its Nature and the Methodology of its Study. Cambridge, MA: MIT Press.

Esteve, R. \& Marquina-Aponte, V. (2011). Children's pain perspectives. Child: Care, Health and Development, 38(3), 441-452.

Fabricius, W. \& Weimer, A. (2010). True or false: Do 5-year-olds understand belief? Developmental Psychology, 46(6), 1402-1416.

Flavell, J., Green, F. \& Flavell, E. (1990). Developmental changes in young children's knowledge about the mind. Cognitive Development, 5(1), 1-27.

Fodor, J. (1998). There Are no recognitional concepts; not even RED. Philosophical Issues, 9, 1-14.

Franck, L., Noble, G. \& Liossi, C. (2010). From tears to words: the development of language to express pain in young children with everyday minor illnesses and injuries. Child: Care, Health and Development, 36(4), 524-533. 
Gaffney, A. \& Dunne, E. (1986). Developmental aspects of children's definitions of pain. Pain, 26(1), 105-117.

Gertler, B. (2009). Introspection. In T. Bayne, A. Cleeremans, P. Wilken (eds.), Oxford Companion to Consciousness. Oxford: Oxford University Press.

Gopnik, A. \& Astington, J. (1988). Children's understanding of representational change and its relation to the understanding of false belief and the appearance-reality distinction. Child Development, 59(1), 26-37.

Grunau, R., Craig, K. (1987). Pain expression in neonates: facial action and cry. Pain, 28(3), 395-410.

Hardcastle, V. (2001). The Myth of Pain. Cambridge, MA: MIT Press.

Harman, G. (1990). The intrinsic quality of experience. In N. Block, O. Flanagan, and G. Güzeldere (eds.) The nature of consciousness, Cambridge, MA: MIT Press.

Hill, C. (2006). Ow! The paradox of pain. In M. Aydede (ed.), Pain: New Papers on its Nature and the Methodology of its Study. Cambridge, MA: MIT Press.

Hill,C. (2009). Consciousness. Cambridge: Cambridge University Press.

Hyman, J. (2003). Pains and places. Philosophy, 73(1), 5-24.

Klein, C. (2007). An imperative theory of pain. The Journal of Philosophy, 104(10), $517-532$.

Kripke, S. (1980). Naming and Necessity. Cambridge, MA: Harvard University Press.

Lewis, D. (1980). Mad pain and Martian pain. In N. Block (ed.), Readings in the Philosophy of Psychology. Cambridge, MA: Harvard University Press, 216-22.

Lycan, W. (1997). Consciousness as internal monitoring. In N. Block, O. Flanagan and G. Güzeldere (eds.) The Nature of Consciousness. Philosophical Debates, Cambridge, MA: MIT Press. 
Lycan, W. (2004). The superiority of HOP to HOT. Advances of Consciousness Research. 56, 93-114.

Martínez, M. (2011). Imperative Content and the Painfulness of Pain. Phenomenology and the Cognitive Sciences, 10, 67-90

Mathew, P., \& Mathew, J. (2003). Assessment and management of pain in infants. Postgraduate Medical Journal, 79(934), 438-443.

McGinn, C. (1982). The character of mind. Oxford: Oxford University Press.

Nichols, S, Stich, S. (2003). How to read your own mind: a cognitive theory of selfconsciousness. In Q. Smith \& A. Jokic (eds.) Consciousness: New Philosophical Perspectives, Oxford: Oxford University Press.

Onishi, K. \& Baillargeon, R. (2005). Do 15-month-old infants understand false beliefs? Science, 308(5719), 255-258.

Pitcher, G. (1970). Pain perception. The Philosophical Review, 368-393.

Reuter, K. (2011). Distinguishing the appearance from the reality of pain. Journal of Consciousness Studies, 18(9-10), 94-109.

Reuter, K, Phillips, D., Sytsma, J. (2014). Hallucinating Pain. in J. Sytsma (ed.), Advances in Experimental Philosophy of Mind, London: Bloomsbury.

Rushforth, J., \& Levene, M. (1994). Behavioural response to pain in healthy neonates. Archives of Disease in Childhood-Fetal and Neonatal Edition, 70(3), 174-176.

Samson, D. \& Apperly, I. (2010). There is more to mind reading than having theory of mind concepts: New directions in theory of mind research. Infant and Child Development, 19(5), 443-454.

Schwitzgebel, E. (2011). Perplexities of Consciousness. Cambridge, MA: MIT Press. 
Seager, W. (2000). Introspection and the elementary acts of mind. Dialogue, 39(1), 5376.

Shoemaker, S. (1996). The first-person perspective and other essays. Cambridge University Press.

Stanford, E., Chambers, C. \& Craig, K. (2005). A normative analysis of the development of pain-related vocabulary in children. Pain, 114, 278-284.

Sullivan, M. (2003). The new subjective medicine: taking the patient's point of view on health care and health. Social Science \& Medicine, 56, 1595-1604.

Sytsma, J. (2010). Dennett's theory of the folk theory of consciousness. Journal of Consciousness Studies, 17(3-4), 107-30.

Taylor, M. \& Flavell, J. (1984). Seeing and believing: children's understanding of the distinction between appearance and reality. Child Development, 55, 1710-20.

Tye, M. (1995). Ten Problems of Consciousness. Cambridge, MA: MIT Press.

Tye, M. (2006). Another look at representationalism about pain. In M. Aydede (ed.), Pain: New Papers on its Nature and the Methodology of its Study. Cambridge, MA: MIT Press.

Vinden, P. (1996). Junín Quechua children's understanding of mind. Child Development, 67(4), 1707-1716. 